\title{
Understanding needs and barriers to using geospatial tools for public health policymaking in China
}

\author{
Dohyeong Kim, ${ }^{1}$ Yingyuan Zhang, ${ }^{1}$ Chang Kil Lee ${ }^{2}$ \\ ${ }^{1}$ School of Economic, Political and Policy Sciences, The University of Texas at Dallas, Richardson, United \\ States; ' Department of Urban Policy and Administration, Incheon National University, Yeonsu-gu, Incheon, \\ Korea
}

\begin{abstract}
Despite growing popularity of using geographical information systems and geospatial tools in public health fields, these tools are only rarely implemented in health policy management in China. This study examines the barriers that could prevent policy-makers from applying such tools to actual managerial processes related to public health problems that could be assisted by such approaches, e.g. evidence-based policy-making. A questionnaire-based survey of 127 health-related experts and other stakeholders in China revealed that there is a consensus on the needs and demands for the use of geospatial tools, which shows that there is a more unified opinion on the matter than so far reported. Respondents pointed to lack of communication and collaboration among stakehold-
\end{abstract}

Correspondence: Chang Kil Lee, Department of Urban Policy and Administration, Incheon National University, Songdo-dong 119 Academy-ro, Yeonsu-gu, Incheon, 22012, Korea.

Tel.: +82.32.835.8739

E-mail: changkillee@incheon.ac.kr

Key words: GIS; Geospatial tools; Public health; Policy-making; Policy implementation; China.

Contributions: the authors contributed equally.

Conflict of interest: the authors declare no potential conflict of interest.

Funding: this work was supported by the Incheon National University International Cooperative Research Grant in 2013.

Ethical approval: the final survey was approved by the Institutional Review Board of the University of Texas at Dallas, TX, USA (MR 17038). All participants in the survey provided informed consent in a written document.

Received for publication: 9 June 2017.

Revision received: 2 December 2017

Accepted for publication: 3 December 2017.

(C) Copyright D. Kim et al., 2018

Licensee PAGEPress, Italy

Geospatial Health 2018; 13:594

doi:10.4081/gh.2018.594

This article is distributed under the terms of the Creative Commons Attribution Noncommercial License (CC BY-NC 4.0) which permits any noncommercial use, distribution, and reproduction in any medium, provided the original author(s) and source are credited. ers as the most significant barrier to the implementation of geospatial tools. Comparison of survey results to those emanating from a similar study in Bangladesh revealed different priorities concerning the use of geospatial tools between the two countries. In addition, the follow-up in-depth interviews highlighted the political culture specific to China as a critical barrier to adopting new tools in policy development. Other barriers included concerns over the limited awareness of the availability of advanced geospatial tools. Taken together, these findings can facilitate a better understanding among policy-makers and practitioners of the challenges and opportunities for widespread adoption and implementation of a geospatial approach to public health policy-making in China.

\section{Introduction}

In recent years, much effort has been made to apply spatial analytic tools to the public health field (Ali et al., 2001). Geospatial tools have been available for health policy-makers and planners to use in policy-making and implementation processes even in low and middle income countries (Rosero-Bixby, 2004; Sugimoto et al., 2007), but the level of adoption varies from field to field as well as from objective to objective. Geographical information systems (GIS) and spatial analysis can be employed both for relatively simple objectives, such as mapping epidemics using global positioning system (GPS) data to track the distribution of infectious agents, e.g. the human immunodeficiency virus (HIV), as done by Coburn and Blower (2013), or complex analyses, such as allocating medical resources and predicting high-risk areas of future disease outbreaks (Kim et al., 2014). An extensive review of the literature on GIS uptake among health care decision-makers and practitioners by Delmelle et al. (2001) highlights two distinct purposes of GIS tools and techniques in the public health framework: i) investigating the factors that cause the spread of a disease; ii) understanding the current, spatial distribution of this disease. The benefits of GIS applications for healthcare and hospital administration as well as for health-decision support systems have been emphasized (Jankowski et al., 2001; Schuurman et al., 2008). It is thus evident that the application of GIS and related geospatial tools has been useful in solving problems and assisting decision-making in the field of public health, as also pointed out by McLafferty (2003).

Despite the benefits of spatial approaches, many countries, such as China, still lag in adoption and implementation of these relevant tools. There are various reasons for that, e.g., it is widely reported that successful implementation of evidence-based prac- 
tices based on scientific tools face obstacles that overshadow the benefits. In addition, the scientific literature identifies several barriers to the adoption of maps and geospatial analysis as decisionmaking tools for health intervention (Delmelle et al., 2001; Kim et al., 2016). Although such barriers slow down the uptake of GIS tools and spatial techniques, possible solutions, such as Health Exploratory Analysis Tool for Practitioners (HELP) have been proposed (Delmelle et al., 2001). Strategies on how to overcome barriers in health policy should be developed based on an understanding of local contexts.

In China, geospatial tools are not widely used in making health-related policy decisions or addressing health issues. Although usage of these approaches for health-related issues are on the rise, geospatial tools are still mostly used for visualization and descriptive purposes. According to the literature, most of the application of spatial methods to health data focus on the basic usage of maps (Li et al., 2014; Zheng et al., 2014), whereas advanced geospatial tools are rarely implemented (Fang et al., 2006; Ali et al., 2007; Van de Poel et al., 2009). Furthermore, while many researchers in China realize that geospatial tools can be effective in disease mapping, predicting outbreaks and allocating health resources, obstacles to their application remain substantial. For example, there is no widespread adoption or implementation of such approaches in the health planning or policy process. This lack of implementation remains problematic despite an increasing number of academic publications utilizing geospatial analysis of health problems (Noor et al., 2009). In addition, there are no strong efforts to examine potential barriers to the adoption or implementation of geospatial tools in Chinese health policy processes.

Here, we first briefly review reported obstacles to the successful adoption of a broad range of scientific implements, including mathematical, statistical, economic and geospatial tools for use in health policy and planning processes. We have categorized these barriers into seven major categories based on the available literature as well as feedback from experts and stakeholders during the initial fieldwork. We then surveyed a group of individuals working in the health sector in China to determine which barriers are more influential in different public health areas and for what health practices spatial tools would be most useful in the Chinese context.

\section{Barriers to the use of spatial tools for public health pol- icy-making}

\section{Unawareness or distrust of benefits}

Scientific tools, including geospatial tools, are unlikely to be adopted when policy-makers do not fully appreciate the limitations of current practices and the remedial role new tools could bring. Without a clear understanding of the value of an alternative approach, the use of such tools cannot be justified. Even if decision-makers agreed to change planning strategy, they often distrust results from geospatial tools as they are felt to be too complicated or they may simply be unfamiliar with map usage (Barndt 1998; Berger 2001). The likelihood of scientific tools being adopted improves when policy-makers are well-informed, understand the beneficial evidence available and thus appreciate the justifications provided.

\section{Complexity of political aspects and competing objectives}

The key to accounting for political factors in the spatial process lies in identifying the objectives of planning. It has been argued that the most difficult challenge for spatial planners is how to reach agreement on an ultimate objective which satisfies the competing agendas of all those involved (Ramasubramanian, 1999). Geospatial tools tend to implicitly guarantee that the recommended solution will be in the best interest of all stakeholders, but it is very difficult to have all stakeholders agree on model objectives and constraints (Rogers and Fiering, 1986).

\section{Lack of adequate communication and collaboration}

Implementation of geospatial research often calls for innovation within the affected organization. However, decision-makers and staff are often culturally resistant to changing existing approaches, particularly in the health field (Brailsford, 2005). They may display psychological resistance to adopting solutions created with scientific methods and instead trust experience, which leads to little attention being paid to evidence-based tools (Rogers and Fiering, 1986). Furthermore, lack of adequate communication and collaboration creates a substantial barrier between researchers and the practitioners who actually implement the policies. In order to overcome any resistance or disinterest from pertinent organizations and facilitate the adoption of geospatial tools, dynamic interaction and constant communication with decision-makers should be promoted (McLafferty, 2003).

\section{Shortage of technical capacity and trained personnel}

A unique challenge to applying geospatial tools in policy planning, particularly in low- and middle-income countries, is the shortage of technical capacity and trained personnel (Taleai et al., 2009). This often includes possible shortages of skilled manpower, of practical experience and of access to research and related technology. The use of geospatial tools can provide opportunities for the transfer of advanced technology to local governments, as it requires a multidisciplinary approach that encompasses economics, geographical information science, computer science, mathematics, system analysis and management (Nedovic-Budic and Pinto, 1999).

The cost of GIS training for personnel tends to be high, both due to the steep learning curve associated with the software and statistical methods needed and to the common shortage of experienced instructors (Delmelle et al., 2001; Schuurman et al., 2008; Walshe, 2017). The literature on primary care personnel training for electronic devices argues that training is often financially inefficient and commonly produces errors (Wang et al., 2003). Considering that GIS or geospatial modelling requires a certain level of technical knowledge, these problems are particularly relevant. Thus, personnel training should be designed as a long-term project supported by substantial technical resources and infrastructure.

\section{Lack of financial capacity and limited budget}

The required degree of investment may be difficult in nonindustrialized settings. The dearth of financial resources makes the accumulation of expertise difficult, since it is costly to bring in outside experts to train in-house personnel. It is similarly expensive to maintain high-quality data management staff and systems (Taleai et al., 2009). Difficulties in meeting such expenses may delay the expedient implementation of spatial tools in planning and problem-solving processes. It is suggested that cooperation with universities and professional organizations in other developed countries could help with the collection of data and information on spatial techniques at a reasonable cost (Haque, 2001). The literature also emphasizes the possibility of local governments selling GIS 
data, which may help obtaining financial resources for hiring spatial specialists. Moreover, the cost of purchasing commercial GIS software, such as ArcGIS, may be an unapproachable burden in low-budget organizations. Even though many researchers take advantage of open-source software or web-based applications as cheaper alternatives, proprietary software is generally used in the traditional desktop settings of governments and health care organizations (Schuurman et al., 2008). High-level geocoding also requires sizable time and cost in order to ensure the positional accuracy of the data (Kim et al., 2008).

\section{Uncertainty due to limited or unreliable data}

Users of spatial tools often face greater uncertainties in the decision environments of low- and middle-income countries than in industrialized ones (Nedovic-Budic and Pinto, 1999). One of the major sources of uncertainty lies in data being limited or unreliable. The public or governmental databases are frequently subject to substantial limitations, such as sharing capacity between different organizations and reliability of database building. In particular, healthcare data are notoriously of poor quality because many healthcare systems still use, at best, old and incompatible computer systems or, at worst, paper-based systems. Extreme care must thus be exercised when using health data (Ali et al., 2001). The lack of high-quality data and access to existing data are fundamental challenges to effective and widespread adoption of spatial techniques for decision support in the health sector (Lin-Fu, 1993; Cockings et al., 2004). This barrier is often exacerbated by concerns about privacy and confidentiality of health-related data, as they tend to contain sensitive personal information. For example, high-resolution spatial health data often allow users to identify the exact locations of patient residences, which violates privacy regulations in most countries (Rushton et al., 2006). Although some methods have been developed to avoid revealing patient location information, they are usually complex and difficult to implement (Boulos et al., 2006; Zimmerman and Pavlik, 2008). Without ample experience in using appropriate methods for disclosure limitation purposes, policy-makers may be hesitant to adopt spatial approaches for routine health policies and practices.

\section{Unwillingness to change}

Successful adoption and implementation of spatial tools in a public health policy-making processes requires health officials to change their decision-making routines. This requires understanding a scientific technique and experience in both implicit and informal learning processes that can require various changes in the daily activities of decision makers. Change not only requires that officials learn from a consultant or expert how to use geospatial tools and interpret results, but also that they learn from their communities about demand and preference for services. This process can cause an unwillingness to change status quo, even if the results are beneficial.

\section{Materials and Methods}

\section{Spatial analysis in China}

We performed a comprehensive literature review as well as a field survey of experts and other stakeholders, not only to learn about current usage of spatial tools in different healthcare sectors in China, but also to identify barriers that challenge widespread adoption of geospatial tools in public health practices in the Chinese context. To achieve a comparative analysis, we classified healthcare sectors into the following eight categories: primary care, drug/vaccination, food/nutrition, emergency care, maternal and child health, environmental health, chronic diseases, and infectious diseases (Yang et al., 2006).

We searched five electronic databases, including Google Scholar, Medline, Web of Science, WHO Library database and PubMed for the English literature and Baidu for Chinese articles. We restricted our search to articles published in the period 20002016 that reported spatial case study results in the healthcare categories listed above. A total of 50 papers were included in the final sample, encompassing all eight healthcare categories. Following the categorization of the level of map usage in the health sector by Kim et al. (2016), these papers were also categorized into three levels of map and spatial analysis usage: basic (visualizing and describing the data), intermediate (extracting spatial patterns and allocating resources) and advanced (predicting future trends and needs). A large number of papers (25 out of 50) also reported case studies related to environmental health, such as air, water and soil pollution by heavy metals and other electronics waste (Wang and Mauzerall, 2006; Leung et al., 2006; Huo et al., 2007; Yu et al., 2007; Li et al., 2014) and parasitic diseases such as schistosomiasis (Zhang et al., 2008; Quan et al., 2017; Zhou et al., 2017). However, geospatial tools were less frequently used in the areas of preventive care and drugs/vaccination.

\section{Stakeholder survey}

We also conducted a survey in November 2016 that included interviews with experts and other stakeholders currently involved in health policy-making processes in China. This target group was made up of government officials, e.g., staff at the Center for Disease Control (CDC), hospital/clinic personnel and other public health policy-makers. The initial questionnaire was developed based on a thorough literature review and barriers to adoption of GIS in the health sector identified in a similar study in Bangladesh (Kim et al., 2016). This allowed us to compare how those barriers are perceived among public health stakeholders and experts in different local contexts. To suit the Chinese context, the initial questionnaire was substantially revised, based on the Chinese literature and in-depth interviews with participants during the initial sampling and questionnaire development process.

The snowball sampling method was used to identify key researchers and stakeholders likely to be knowledgeable about the topic. We first identified ten individuals in three different job categories (government, clinics and research institutions) who would be willing to participate. We subsequently requested that they identify additional individuals in the field who could provide valuable information regarding the questions asked in the survey. This initial group of participants was also involved in the process of finalizing the questionnaire so that we could incorporate their feedback and perspective. The final sample included a total of 127 respondents from 27 cities in 10 different provinces, out of which 37 respondents were officials of the government or CDC, 83 worked in hospitals/clinics and 7 in other public health areas such as research institutions. Eighty-seven respondents were male and 40 were female. Twenty-five respondents were between 22 and 30 years old, 43 were between 31-40 years old, and 59 were above 40 years old. Sixty-four of the respondents had high-level administrative positions while the rest worked as entry-level officers, nurses, clinicians or researchers. 
All respondents in the final sample completed the survey using a five-point Likert scale (Likert, 1932) (1=strongly disagree, $2=$ disagree, $3=$ neutral, $4=$ agree, $5=$ strongly agree) when responding to three major questions: i) Evaluation in the Chinese context whether they agreed or not with each of the seven barriers mentioned; ii) Recommendation regarding the appropriate level of geospatial approach (basic, intermediate or advanced) in China, based on their knowledge and experience, for each of the eight different healthcare sectors (responses were compared with what was found in the literature in order to identify any mismatch between what was suggested by researchers and what was practically needed by policy-makers and practitioners); iii) Ranking (on a scale from 1 to 7) of the necessity and importance of GIS and other geospatial approaches for the seven possible areas of health-related policy-making and intervention, a question also asked in the Bangladesh survey (Kim et al., 2016). The results from both surveys (in China and in Bangladesh) were compared to identify differences between the two countries.

The survey results were followed up through in-depth interviews with five Chinese experts in the public health field and elaborated on the results of our findings based on their insight.

\section{Results}

Nearly all of the respondents (125 out of 127) mentioned that they had not used spatial approaches in their decision-making or practices, but all of them agreed that geospatial tools could be useful. However, a clear distinction was found in the attitude towards the barriers. Figure 1 shows that, for all types of barriers, the responses from hospital/clinic staff were higher with a smaller variability than government (CDC) employees, which indicates that experts working in clinical settings in China found the barriers more obstructive than those in the public health setting. Financial limitation was regarded as the most significant barrier for government employees, while lack of adequate communication and collaboration among stakeholders was the primary concern for experts working in medical settings. Moreover, financial restriction and limited data were found to be the most critical common issues for both types of respondents (mean scores $>3$ ).

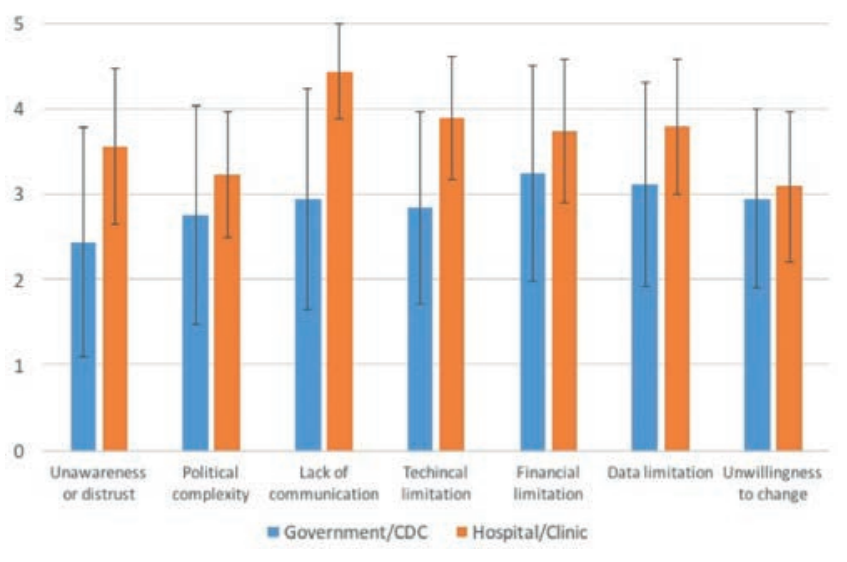

Figure 1. Barriers to using spatial tools for evidence-based health policy: government employees $v s$ hospital/clinic staff.
Figure 2 illustrates that, for every healthcare sector, there is a gap in the use level of geospatial tools between what was reported in the literature and what was recommended by the stakeholders. For instance, in primary care, emergency care and chronic disease, only a basic level of geospatial application was found in the literature whereas a substantial portion of respondents suggested an intermediate or an advanced level of spatial application in health intervention. Although some literature references used an intermediate or advanced level of spatial tools for food/nutrition, maternal and child health, and environmental health cases in China, it was not as desired by the respondents. Drug/vaccination was the only sector where advanced spatial tools were more widely used in the literature than desired by the respondents.

Figure 3 reveals a significant difference between the respondents in China and those in Bangladesh with regard to the preferred objectives for public health policy and how geospatial tools should be utilized. Overall, Bangladeshi experts were more aware of the importance and benefits of spatial approaches in achieving most health policy objectives. This disparity reflects the fact that $78 \%$ of the respondents in the Bangladesh survey mentioned that they had some level of experience in using maps or spatial data of some sort, while only $2 \%$ of Chinese respondents had used geospatial approaches. Contrary to the Bangladeshi respondents, who were more likely to desire using geo spatial tools to improve health service availability or identify communities with a lack of health services, the Chinese respondents focused more on allocating resources for health programmes. Despite the limitations of the inter-country comparison due to the use of two separate surveys, this analysis sheds light on the current status of geospatial public health application in the two countries.

The in-depth interviews confirms the need for geospatial tools in implementing some public health policies, such as infectious disease policy, and highlights the three most critical barriers to using spatial tools for public health policy-making in China. First, all interviewees pointed to political barriers with respect to replacing old tools with new. Given this outcome, the advantages of geospatial tools do not seems sufficient for change, but political or economic incentives for Chinese employers may be needed for them to give up the old tools. Accordingly, experts would advise the central government to offer political incentives for the public health sector to achieve a broader implementation of innovative

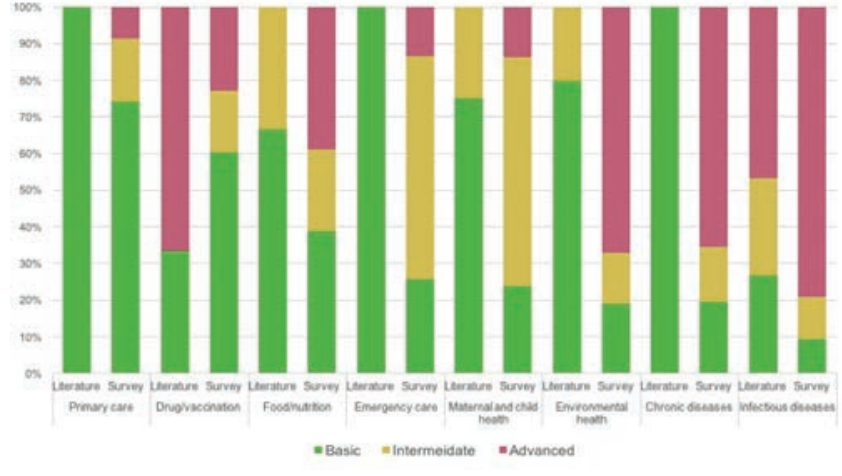

Figure 2. Use level of spatial tools by healthcare sectors: literature vs survey results. 
spatial tools. Another barrier was the disconnect between government policy-makers and research experts. Most of the interviewees indicated that they did not communicate with academic researchers when they made policy decisions. Some reported inviting academic scholars to advise government officers in the process of developing new policies, but this was not common in the field of public health. Interviewees stressed the need to building bridges between academia and government as an issue that deserves further attention. The last key barrier was a lack of knowledge about spatial tools and their implementation among policy-makers in China. Most public health policies are determined by government agencies, which tend to have little experience and knowledge about advanced policy support tools. For obvious reasons, individuals less familiar with these tools, and ignorant of their advantages, are less likely to choose to use them.

\section{Discussion}

Academic researchers, policy-makers, and practitioners have become more interested in applying GIS and other geospatial tools to enhance the effectiveness and transparency of decision-making and implementation processes in a variety of public health policy areas. However, it is widely reported that policy-makers and planners who have actually used spatial tools, have also faced obstacles to their successful application, often overshadowing the potential benefits. This study highlights expert opinion about what barriers could prevent policy-makers in China from implementing geospatial tools in policy development processes and what areas of public health policy should be prioritized for geospatial application. Despite infrequent use of such tools in Chinese policy-making, it seems evident that the needs and demands for geospatial approaches are substantial. To facilitate a widespread adoption of these tools in health policy-making, the level of communication and collaboration among stakeholders must be enhanced.

The findings from this study provide direction on how national and local governments in China might handle potential obstacles to the adoption and implementation of geospatial tools in addressing the various public health challenges faced in evidence-based policy-making. In particular, comparing the reports of spatial approaches in Chinese academic literature with the perceptions of

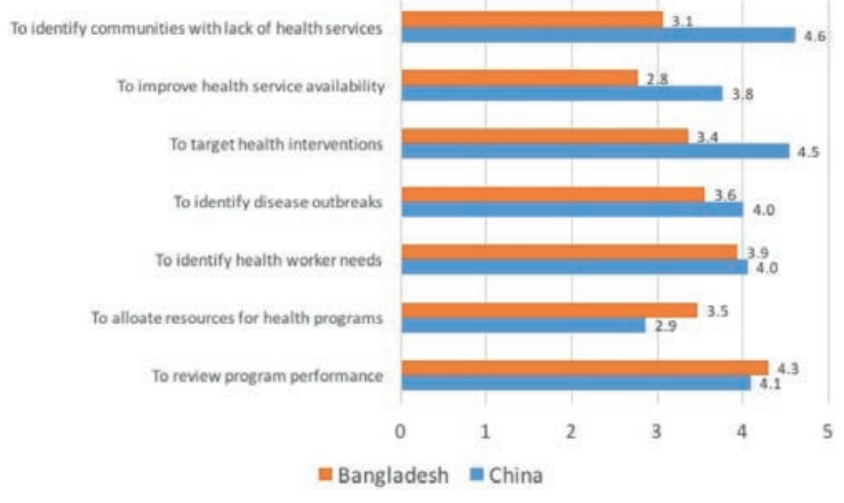

Figure 3. Prioritized objectives of spatial health applications: Bangladesh vs China. From $1=$ most important to $5=$ least important.
Chinese experts clarifies the mismatch between the focus of the academic community and clinical and public health needs. This study could serve as a guide for the global public health community and consultants who intend to facilitate the widespread use of geospatial tools in public health in low-and middle-income countries. The comparison between the Chinese and Bangladeshi surveys presented in this paper demonstrates the potential benefit of a large-scale, multi-country study on this topic.

Comparison of the responses from stakeholders in China and Bangladesh reveals differences in priorities between the two Asian countries. The most important concern for Chinese experts was how to best allocate resources to health programmes, while in Bangladesh it was how to improve health service availability by identifying under-served areas. Such difference in priorities could partly be due to varying levels of familiarity with geospatial tools. In fact, the first relevant literature reports on the use of geospatial techniques were published in the late 1990s and the early 2000s (Tang et al., 1998; Van Geen et al., 2003; Hassan, 2005), at a time when spatial tools were already widely used for various health topics in Bangladesh, e.g., health services, cholera epidemics and use of contraceptives (Siddique et al., 1991). It appears that public health professionals in China are still in the beginning stages of geospatial tool usage, though some experts in China have started to use more advanced geospatial tools to solve problems related to health (Pan et al., 2015; Wang et al., 2016; Xiong and Luo, 2017; Li et al., 2017). The in-depth interviews provided tangible guidance to public health policy-makers in China. Considering the substantial benefits of using geospatial tools to support public health policy-making, the Chinese Government may need to consider policies that provide sufficient political incentives for the public health sector to implement such tools and thereby better allocate public health resources. It is also important for government officials in China to actively communicate with researchers in order to improve policy. Likewise, it is also crucial for expert researchers in the public health field to form and cultivate governmental connections. Offering policy-makers short-term training or education on spatial concepts and analytic tools may be another way to close the knowledge gap.

The generalizability of this study's findings is limited since we did not use a nationally representative sample. However, we hope this paper forms the basis for a subsequent study with a more concrete strategy and action plans for the extensive utilization of spatial approaches, which may provide insights to those in charge of public health services in China and other Asia-Pacific countries. Future studies should explore the political, institutional and cultural barriers specific to each individual public health issue, possibly by using in-depth interviews with policy-makers.

\section{Conclusions}

Seven different forms of barriers to the implementation of geospatial tools in the health sector were identified. Considering the limited scope of GIS uptake in China, our research and efforts to understand the opinions of various stakeholders, from healthcare administrators to researchers, should provide guidance for Chinese health professionals in various sectors to more often attempt enhancing experience by adopting and implementing geospatial tools. 


\section{References}

Ali M, Emch M, Ashley C, Streatfield PK, 2001. Implementation of a medical geographic information system: Concepts and uses. J Health Popul Nutr 19:100-10.

Ali M, Jin Y, Kim DR, De ZB, Park JK, Ochiai RL, Dong B, Clemens JD, Acosta CJ, 2007. Spatial risk for gender-specific adult mortality in an area of southern China. Int J Health Geogr $6: 31$.

Barndt M, 1998. Public participation GIS-Barriers to implementation. Cartogr Geogr Inform 25:105-12.

Berger T, 2001. Agent-based spatial models applied to agriculture: a simulation tool for technology diffusion, resource use changes and policy analysis. Agr Econ 25:245-60.

Boulos MN, Cai Q, Padget JA, Rushton G, 2006. Using software agents to preserve individual health data confidentiality in micro-scale geographical analyses. J Biomed Inform 40:52-76.

Brailsford S, 2005. Overcoming the barriers to implementation of operations research simulation models in healthcare. Clin Invest Med 28:312.

Coburn BJ, Blower S, 2013. Mapping HIV epidemics in subSaharan Africa with use of GPS data. Lancet Glob Health 1:e251.

Cockings S, Dunn CE, Bhopal RS, Walker DR, 2004. Users' perspectives on epidemiological, GIS and point pattern approaches to analyzing environment and health data. Health Place 10:169-82

Delmelle E, Delmelle EC, Casas I, Barto T, 2001. H.E.L.P: A GISbased health exploratory analysis tool for practitioners. Appl Spat Anal Polic 4:113-37.

Fang L, Yan L, Liang S, de Vlas SJ, Feng D, Han X, Zhao W, Xu B, Bian L, Yang H, 2006. Spatial analysis of hemorrhagic fever with renal syndrome in China. BMC Infect Dis 6:1.

Haque A, 2001. GIS, public service, and the issue of democratic governance. Public Admin Rev 61:259-65.

Hassan MM, 2005. Arsenic poisoning in Bangladesh: spatial mitigation planning with GIS and public participation. Health Policy 74:247-60.

Huo X, Peng L, Xu X, Zheng L, Qiu B, Qi Z, Zhang B, Han D, Piao Z, 2007. Elevated blood lead levels of children in Guiyu, an electronic waste recycling town in China. Environ Health Persp 115:1113-7.

Jankowski P, Andrienko N, Andrienko G, 2001. Map-centred exploratory approach to multiple criteria spatial decision making. Int J Geogr Inf Sci 15:101-27.

Kim D, Lauria DT, Poulos C, Dong B, Whittington D, 2014. Effect of travel distance on household demand for typhoid vaccines: implications for planning. Int J Health Plan M 29:e261-e76.

Kim D, Galeano MAO, Hull A, Miranda ML, 2008. A framework for widespread replication of a highly spatially resolved childhood lead exposure risk model. Environ Health Persp 116:1735-9.

Kim D, Sarker M, Vyas P, 2016. Role of spatial tools in public health policymaking of Bangladesh: opportunities and challenges. J Health Popul Nutr 35:1.

Leung A, Cai ZW, Wong MH, 2006. Environmental contamination from electronic waste recycling at Guiyu, southeast China. J Mater Cycles Waste 8:21-33.

Li P, Ge M, Jing J, Wei D, 2017. Regional variation of alanine aminotransferase serum levels in the People's Republic of China. Geospat Health 12:335-41.
Li Z, Ma Z, van der Kuijp TJ, Yuan Z, Huang L, 2014. A review of soil heavy metal pollution from mines in China: pollution and health risk assessment. Sci Total Environ 468:843-53.

Likert R, 1932. A techinque for the measurement of attitudes. Arch Psychol 22:1-55.

Lin-Fu JS, 1993. Asian and Pacific Islander Americans: an overview of demographic characteristics and health care issues. Asian Am Pac Isl J Health 1:20-36.

McLafferty SL, 2003. GIS and health care. Annu Rev Publ Health 24:25-42.

Nedovic-Budic Z, Pinto JK, 1999. Understanding interorganizational GIS activities: A conceptual framework. URISA 11:5364.

Noor AM, Alegana VA, Gething PW, Snow RW, 2009. A spatial national health facility database for public health sector planning in Kenya in 2008. Int J Health Geogr 8:1.

Pan J, Liu H, Wang X, Xie H, Delamater PL, 2015. Assessing the spatial accessibility of hospital care in Sichuan Province, China. Geospat Health 10:384.

Quan J, Zhao D, Liu L, Chen Y, Zhou J, Jiang Y, Du X, Zhou Z, Akova M, Yu Y, 2017. High prevalence of ESBL-producing Escherichia coli and Klebsiella pneumoniae in communityonset bloodstream infections in China. J Antimicrob Chemoth 72:273-80.

Ramasubramanian L, 1999. GIS implementation in developing countries: learning from organisational theory and reflective practice. T GIS 3:359-80.

Rogers PP, Fiering MB, 1986. Use of systems analysis in water management. Water Resour Res 22:146S-58S.

Rosero-Bixby L, 2004. Spatial access to health care in Costa Rica and its equity: a GIS-based study. Soc Sci Med 58:1271-84.

Rushton G, Armstrong MP, Gittler J, Greene BR, Pavlik CE, West MM, Zimmerman DL, 2006. Geocoding in Cancer Research: A Review. Am J Prev Med 30:S16-S24.

Schuurman N, Leight M, Berube M, 2008. A web-based GUI for evidence-based decision making for health care allocations in rural areas. Int J Health Geogr 7:49.

Siddique A, Baqui A, Eusof A, Haider K, Hossain M, Bashir I, Zaman K, 1991. Survival of classic cholera in Bangladesh. Lancet 337:1125-7.

Sugimoto JD, Labrique AB, Ahmad S, Rashid M, Klemm RD, Christian P, West KP, 2007. Development and management of a geographic information system for health research in a developing-country setting: a case study from Bangladesh. J Health Popul Nutr 25:436-47.

Taleai M, Mansourian A, Sharifi A, 2009. Surveying general prospects and challenges of GIS implementation in developing countries: a SWOT-AHP approach. J Geogr Syst 11:291-310.

Tang D, Ni I, Müller-Karger F, Liu Z, 1998. Analysis of annual and spatial patterns of CZCS-derived pigment concentration on the continental shelf of China. Cont Shelf Res 18:1493-515.

Van de Poel E, O’Donnell O, Van Doorslaer E, 2009. Urbanization and the spread of diseases of affluence in China. Econ Hum Biol 7:200-16.

Van Geen AF, Zheng Y, Versteeg RJ, Stute M, Horneman AH, Dhar RK, Steckler MS, Gelman AE, Small C, Ahsan H, 2003. Spatial variability of arsenic in 6000 tube wells in a $25 \mathrm{~km}^{2}$ area of Bangladesh. Water Resour Manag 39:1140-51.

Walshe N, 2017. Developing trainee teacher practice with geographical information systems (GIS). J Geogr Higher Educ 41:608-28. 
Wang SJ, Middleton B, Prosser LA, Bardon CG, Spurr CD, Carchidi PJ, Kittler AF, Goldszer RC, Fairchild DG, Sussman AJ, Kuperman GJ, Bates DW, 2003. A cost-benefit analysis of electronic medical records in primary care. Am J Med 114:397-403.

Wang X, Mauzerall DL, 2006. Evaluating impacts of air pollution in China on public health: implications for future air pollution and energy policies. Atmos Environ 40:1706-21.

Wang Y, Yang Y, Shi X, Mao S, Shi N, Hui X, 2016. The spatial distribution pattern of human immunodeficiency virus/acquired immune deficiency syndrome in China. Geospat Health $11: 414$

Xiong X, Luo L, 2017. Use of geographical information systems for delimiting health service areas in China. Geospat Health 12:486.

Yang G, Rao C, Ma J, Wang L, Wan X, Dubrovsky G, Lopez AD, 2006. Validation of verbal autopsy procedures for adult deaths in China. Int J Epidemiol 35:741-8.
Yu G, Sun D, Zheng Y, 2007. Health effects of exposure to natural arsenic in groundwater and coal in China: an overview of occurrence. Environ Health Persp 115:636-42.

Zhang Z, Carpenter TE, Chen Y, Clark AB, Lynn HS, Peng W, Zhou Y, Zhao G, Jiang Q, 2008. Identifying high-risk regions for schistosomiasis in Guichi, China: a spatial analysis. Acta Trop 107:217-23.

Zheng N, Guo Y, Padmadas S, Wang B, Wu Z, 2014. The increase of sexually transmitted infections calls for simultaneous preventive intervention for more effectively containing HIV epidemics in China. BJOG-Int J Obstet Gy 121(:35-44.

Zhou L, Ren R, Yang L, Bao C, Wu J, Wang D, Li C, Xiang N, Wang Y, Li D, 2017. Sudden increase in human infection with avian influenza A (H7N9) virus in China, SeptemberDecember 2016. Western Pac Surveill Response 8:6-14.

Zimmerman DL, Pavlik C, 2008. Quantifying the effects of mask metadata disclosure and multiple releases on the confidentiality of geographically masked health data. Geogr Anal 40:52-76. 